\title{
Against carceral data collection in response to anti-Asian violences
}

Big Data \& Society

January-June: $1-6$

(c) The Author(s) 2021

Article reuse guidelines:

sagepub.com/journals-permissions DOI: $10.1 \mid$ 177/205395|72|1028252

journals.sagepub.com/home/bds

@SAGE

\author{
Rachel Kuo' and Matthew Bui ${ }^{2,3}$
}

\begin{abstract}
This commentary reflects on recent instances of anti-Asian violence and state responses to redress violence through data-driven strategies. Data collection often presents itself as an appealing strategy, due to impacted communities' desires for evidence and metrics to substantiate political claims. Yet, data collection can bolster the carceral state. This commentary takes an antagonistic approach to policing, including the ongoing creation of data infrastructures byand for-law enforcement through hate crimes legislation. We critically discuss the challenges and possibilities in building towards anti-carceral responses amidst ongoing racial violence and crisis.
\end{abstract}

\section{Keywords}

Asian American, race, policing, COVID-19, racism, data collection

Since the start of the COVID-19 pandemic, incidents of racism against Asians and Asian Americans increased, including highly visible incidents of physical violence. These attacks sparked outcry on the need for resources and infrastructures to respond to anti-Asian violence. On 16 March 2021, the mass shooting at Asian-owned massage parlors and spas in Atlanta, GA intensified attention on these racist attacks. The shooter targeted the parlors to eliminate a "temptation" that fueled his "sexual addiction" (Kaur, 2021). The shootings resulted in the death of eight people, six of whom were Asian women. Widely reported was the Atlanta Police Department's inability to reconcile the incident as racially motivated, which overemphasized attention on police capacity and competency in understanding "hate crimes".

Different forms of data collection-qualitative and quantitative - have been central to the narrativization of anti-Asian violence during the pandemic. The reporting tool, Stop AAPI Hate, has been one of the most widely cited and promoted, drawing on community and academic networks and supporting local data projects (Takasaki, 2020). By March 2021, they had collected nearly 3800 reports ranging from verbal harassment, avoidance in public spaces, to physical attacks. This is a broad range of incidents under the category of "hate" and comes at a time when the criminalization of hate is expanding with increasingly severe consequences (Nopper, 2021). Additionally, the circulation of exceptional violence on social media platforms obfuscates the slow and quiet forms of state violence while also bolstering white supremacy. While incidents of physical assaults have received heightened attention, there are different scales and degrees of violence largely absent in media discussions about antiAsian racial violence: labor and economic exploitation, inadequate social safety nets, and immigrant detention and deportation (Kuo and Bhaman, 2021).

Desires for evidence and metrics to substantiate and mobilize political claims make data collection an appealing strategy and solution (Dourish and Gómez Cruz, 2018). However, data projects can bolster the carceral state, reifying and producing racial violence (Browne, 2015; Muhammad, 2010). Carceral data,

\footnotetext{
'University of North Carolina, Chapel Hill, NC, USA

${ }^{2}$ Alliance for Public Interest Technology, New York University, New York, NY, USA

${ }^{3}$ School of Information, University of Michigan, Ann Arbor, MI, USA
}

\section{Corresponding author:}

Rachel Kuo, Center for Technology, Information, and Public Life, School of Library and Information Science, University of North Carolina, 100 Manning Hall, CB 3360, Chapel Hill, NC 25799, USA.

Email: rachel.kuo@nyu.edu 
including police data surveillance and hate crimes data collection, are part of what Tonia Sutherland (2019) describes as a carceral archive, sustained through law enforcement practices to perpetuate narratives justifying incarceration. More broadly, data collection for policing is part of the long history of carceral technologies that control, capture, and exile categories of people, and are sustained by industries and institutions that "exploit visibility and exposure" under the guise of security (Carceral Tech Resistance Network, 2021). This commentary on data-driven responses to antiAsian violences takes an antagonistic approach to policing, including the ongoing creation of data infrastructures by - and for-law enforcement through hate crimes legislation. Below, we critically discuss the challenges and possibilities in building towards anticarceral responses amidst ongoing racial violence and crisis.

\section{Challenging data and policing as solutions to anti-Asian violence}

In the midst of heightened racial violence, carcerality is used to advance "civil rights". After the Atlanta shootings, police departments deployed units to Chinatowns and Asian neighborhoods across US cities. In New York City, the NYPD's Counterterrorism unit, which was established after 9/11, deployed "assets" to Asian communities "out of an abundance of caution" (@NYPDCounterterrorism, 2021). The NYPD also increased Asian plainclothes undercover officers (a unit they had started disbanding in the midst of Summer 2020 uprisings against police violence).

Additionally, the@NYPDHateCrimes Twitter account circulates images of unidentified individuals to seek tips on racial attacks and share updates when people are arrested; almost all images have been of Black men. These vigilante styles of communityinformed policing utilize carceral data regimes connecting city surveillance apparatuses to social media platforms. On social media, imagery of brutal violence proliferates (Nguyen, 2021; Richardson, 2020). One video included a 65-year-old Filipina woman being publicly attacked; one of the most disturbing aspects of the video was the lack of public intervention. Later, news coverage and police reports shared that the arrested attacker was Black, unhoused, and recently out on parole after being incarcerated for 19 years. These media depictions leverage and exacerbate Black and Asian conflict to exploit narratives of Black criminality to justify policing. Here, we also want to draw attention to how exceptional forms of violence co-exist with slower, less visible forms of violence. In New York City, many of the people arrested for anti-Asian violence have had histories of mental illness and homelessness (Hong et al., 2021). Generally, there is a considerable lack of access to safe housing, adequate support after release from prisons and jails, and noncoercive mental health care. Arresting people who experience vulnerability and precarity does not interrupt ongoing cycles of violence and instead perpetuates harm (Law, 2021; Ortiz and Jackey, 2019).

State responses to anti-Asian violence during the pandemic have emphasized expanding data-driven law enforcement to address the threat of hate. For example, in August 2020, the NYPD created the Asian Hate Crime Task Force with Asian American officers to better track racist attacks due to "underreporting" from communities. Additionally, concerns surrounding "incomplete datasets" given nonreporting or underreporting to police can create conditions where data collection outside of law enforcement, such as emergency medical response data and commercial camera footage, can become used to track crime in lieu of police data (Hibdon et al., 2021). At the national level, President Biden's January 2021 memorandum on combating anti-Asian racism emphasized the need to "expand collection of data and public reporting regarding hate incidents" (White House, 2021a). Two weeks after the Atlanta shootings, the administration announced that the Department of Justice (DOJ) would implement crossagency initiatives responding to anti-Asian violence, including expanding the Crime Data Explorer tool on hate crime statistics and adding categories of crimes and demographic data (White House, 2021b). Additional efforts also included "civil rights trainings" developed by the Community Oriented Policing Services department. Passed in May 2021, the COVID-19 Hate Crimes Act provides guidance for law enforcement to: establish online reporting across multiple languages, expand "culturally competent" education campaigns, and expand data collection and reporting (COVID-19 Hate Crimes Act, 2021). These resources illustrate how policing exploits crises: that is, language translation tied to policing practices (i.e. programs for "strategic languages", such as Arabic, Urdu, Pashto, and Farsi, to police communities) are promoted while simultaneously unavailable for other necessary public services.

\section{'Hate has no home here': Carceral data regimes}

While data collection and documentation can be important tools for providing critical counternarratives by marginalized communities, these practices must be done with attention to potential harm 
(Collier, 2020; Richardson, 2020). "Inclusive" datadriven practices can reify exclusions and be used as tools for dispossession and displacement (Hoffman, 2020; Kauanui, 2008). Data-driven processes have been linked to how different groups can advocate for public resources and benefits, where the collection and analysis of data about racially marginalized communities can legitimate political claims. Within Asian and Asian American communities, different diasporic groups are impacted by racial categorization schemas, revealing the limitations of state-based forms of recognition. For example, aggregated data obscures disparities across ethnicity, income, education, and employment, rendering some communities hypervisible and others invisible for resource allocation (Runes, 2017). Additionally, institutional data collection tends to mostly benefit external state and NGO actors while only providing "incremental gains" for marginalized communities (Heeks and Shekhar, 2019). Uses of data to make decisions about distributing social services can also replicate racially punitive logics of social control (Nopper, 2019; Roberts, 2020). Thus, data can present a "double bind" for communities when entangled with advocacy (Crooks and Currie, 2021).

The state turned to big data as a response to antiAsian violence: to get better at collecting and analyzing "hate crime" data. These data practices emerged through the 1990 Hate Crimes Statistics Act, notably one of the first federal statutes that recognized categories of sexual orientation-legitimizing identity categories through recognition by police and prosecution. This act, expanded through the 1994 Crime Bill, also included disability as a category for data collection while also increasing harsher sentencing. Hate crime statistics and data collection converge classification and control. In 2009, hate crime legislation extended to include and "protect" gender, sexuality, and disability through the Matthew Shepard and James Byrd Hate Crimes Prevention Act. Passed under the National Defense Authorization Act, this bill linked the expansion of "tolerance" and "equality" to military expenditure (Reddy, 2011; Sylvia Rivera Law Project, 2009). The reduction of hate into individualized forms of violence and patriotic outcries of "hate has no home here" elides how origins of "Asian hate" have also been statedriven by US police, border patrol, and militarism (Rodriguez, 2021). Hate crimes legislation bolsters systems of criminalization and obscures the violence of policing (Asian American Feminist Collective, 2020; GAPIMNY, 2021).

Data collection by law enforcement to police and surveil communities of color is not new. These practices are rooted in the long legacy of anti-Black racism in the US and embedded into contemporary data-driven technologies (Browne, 2015). Additionally, state investment in data infrastructures, such as national quotas and registration systems, to police, incarcerate, and deport Asian and Asian Americans as terror threats, criminals, and "illegal" has been long-standing (Bayoumi, 2015; Ngai, 2004). The creation of carceral data regimes in the "war against hate" builds on US police and military infrastructure that are activated by racism and xenophobia (Husain, 2020). Rooting out hate domestically justifies ongoing militarized policing and transnational warfare, including geopolitical tensions with China that exacerbate anti-Asian racism within the US.

Government responses to end white supremacy have focused on extreme acts of violence and have used the framework of "combatting" domestic terrorism, particularly countering violent extremism (CVE). Funded through the Department of Homeland Security, CVE leverages the language of "violence prevention" and "community engagement" by giving grants to community and law enforcement organizations in exchange for information about "suspected" individuals (Michel, 2015). Essentially, we are witnessing a repurposing of War on Terror infrastructures created in the wake of $9 /$ 11, where the surveillance and policing of Muslims and Arab Americans have been a key component of US counterterrorism efforts (Kundnani, 2014; Muslim Justice League, 2020). Finally, data and transparency initiatives fail in curtailing violence by police ( 8 to Abolition, 2020; Stop LAPD Spying, 2020). The long history of abolition movements and, more recently, the 2020 uprisings against police violence, have demonstrated the necessity of divesting from police towards resourcing alternative infrastructures.

\section{Policing won't save us}

In holding a vision and commitment to a future without carceral systems, we challenge the notion that law enforcement, including more data collection and training, will end anti-Asian violence. We need responses to violence without enacting further violence. Black feminist abolitionist Mariame Kaba (2017) points out the difference between safety and security by observing that people often feel "secure" through using tools and corresponding institutions, from weapons and policing, that reproduce violence. Considering this, we call for alternative responses that do not expand police resources, systems of criminalization, and take away resources from the most vulnerable. Rather than the highly individualized frame of "stopping hate" (Whitlock and Bronski, 2015), we emphasize the need to invest in community resources, structures, and practices that redress violence through "care not cops" models (8 to Abolition, 2020; Care Not Cops, 2017). Currently, many community organizations do not have the adequate resources for sustainable alternatives; 
often, existing funding structures for anti-violence work rely on municipal and federal funds linked to forms of policing (Hossain and Mon, 2020).

While we advocate for community safety resources, the proliferation of data does not interrogate, nor eradicate, underlying systems of violence. The DOJ will be launching a hate crimes grants program to fund partnerships with law enforcement and prosecution agencies to increase trust and reporting (Bureau of Justice Assistance, 2021). This program encourages university partnerships; such a program is one of many that resources law enforcement partnerships with community groups and universities. Researchers must not collude with carceral data projects that further enact violence upon communities of color, especially university researchers' past contributions to, and benefitting from, such projects. Beyond critically examining the role of big data in political claims-making, we believe in engaging in practices of refusal (Barabas, 2020; Cifor et al., 2019).

Relatedly, we emphasize the decoupling of social services, including community resources for safety and well-being, away from law enforcement agencies. In the midst of continued economic crisis and to redress slower forms of violence, there may be ways forward for noncarceral, community-led data projects for racial justice. For example, historical and current uses of worker testimonials function as "crucial media" to document labor exploitation (Lowe, 1998). Or, projects like the Anti-Eviction Mapping Project have combined multiple data sources to advocate for tenants and track predatory and negligent landlords. Other examples include mutual aid groups who manage community data to coordinate and distribute groceries and medical supplies within neighborhoods.

In sum, law enforcement and police data are not the solution for safety nor for redressing anti-Asian violence. Since we began writing this commentary in the aftermath of the Atlanta shootings, we have seen a mass shooting at a FedEx facility in Indianapolisfour of the victims are Sikh and a majority of workers are from the Sikh community, a community that has experienced racist targeting after 9/11. We have also seen the deaths of Black and brown youth by policeDaunte Wright, Adam Toledo, and Ma'Khia Bryant. These are not random acts of violence. Mass shootings, white supremacist attacks on people of color, militarized policing, and the use of military force by the US globally are all interconnected (Purnell, 2019). Throughout the pandemic, we have led and participated in numerous community workshops, conversations, and debates about visions for safety. We are often asked: What options will we have, if not the police? Reflecting on this question (and its assumptions) can open up new possibilities. Echoing many activists' and organizers' calls: the police won't save us; neither will carceral data.

\section{Acknowledgements}

This commentary emerged from the authors' participation in a plenary panel on "Building Solidarity Against Anti-Asian Violence" at the 2021 Association for Asian American Studies Conference. The authors are grateful to the co-creators of the 8 to Abolition project, the Carceral Tech Resistance Network, and the Asian American Feminist Collective for the ongoing conversations that shape these ideas and themes.

\section{Declaration of conflicting interests}

The author(s) declared no potential conflicts of interest with respect to the research, authorship, and/or publication of this article.

\section{Funding}

The author(s) received no financial support for the research, authorship, and/or publication of this article.

\section{References}

8 to Abolition (2020) 8 to Abolition. Available at: www.8toa bolition.com/ (accessed 1 June 2021).

Asian American Feminist Collective (2020) We want cop-free communities: Against the creation of an Asian hate crime task force by the NYPD. Medium, 3 September. Available at: https://aafcollective.medium.com/we-wantcop-free-communities-3924956251a2 (accessed 1 June 2021).

Barabas C (2020) To build a better future, designers need to start saying 'No'. One Zero, 13 October. Available at: https://onezero.medium.com/refusal-a-beginning-thatstarts-with-an-end-2b055bfc14be (accessed 1 June 2021).

Bayoumi M (2015) This Muslim American Life: Dispatches from the War on Terror. New York: NYU Press.

Browne S (2015) Dark Matters: On the Surveillance of Blackness. Durham, NC: Duke University Press.

Bureau of Justice Assistance (2021) Matthew Shepard and James Byrd, Jr. Hate Crimes Program. Available at: https://bja.ojp.gov/program/shepard-byrd-hate-crimesprogram/funding

Carceral Tech Resistance Network (2021) Why. CTRN, Available at: www.carceral.tech/why

Care Not Cops (2017) Care Not Cops. Available at: www. carenotcops.org/ (accessed 1 June 2021).

Cifor M, Garcia P, Cowan TL, et al. (2019) Feminist data manifest-no. Available at: www.manifestno.com (accessed 7 June 2021).

Collier Z (2020) Legacy in action. In: The Role of Archives in Transformation, Community, and Healing During a Pandemic. Archival Outlook Magazine, Society of American Archivists, p. 28.

COVID-19 Hate Crimes Act (2021) S.937 - 117th Congress. Crooks R and Currie M (2021) Numbers will not save us: Agonistic data practices. The Information Society.

Dourish P and Gómez Cruz E (2018) Datafication and data fiction: Narrating data and narrating with data. Big Data \& Society 5(2).

GAPIMNY (2021) 100+ Asian and LGBTQ Organizations' Statement in Opposition to Law Enforcement-Based Hate 
Crime Legislation. Reappropriate, 12 May. Available at: http://reappropriate.co/2021/05/75-asian-and-lgbtq-organ izations-statement-in-opposition-to-law-enforcementbased-hate-crime-legislation/\#more-32106 (accessed 7 June 2021).

Heeks R and Shekhar S (2019) Datafication, development and marginalised urban communities: an applied data justice framework. Information, Communication, and Society 22(7): 992-1011. https://doi.org/10.1080/ 1369118X.2019.1599039

Hibdon J, Telep C and Huff J (2021) "Going beyond the blue: The utility of emergency medical services data in understanding violent crime". Criminal Justice Review. https:// doi.org/10.1177/0734016821999700.

Hoffmann AL (2020) Terms of inclusion: Data, discourse, violence. New Media \& Society. https://doi.org/10.1177/ 1461444820958725.

Hong N, Southhall A and Watkins A (2021) He was charged in an Anti-Asian attack. It was his 33rd arrest. New York Times, 6 April. Available at: www.nytimes.com/2021/04/ 06/nyregion/nyc-asian-hate-crime-mental-illness.html (accessed 3 June 2021).

Hossain S and Mon M (2020) South Asians for abolition: Diasporic strategies and conversations. In: Asian American writers' workshop: The Margins, 16 December. Available at: https://aaww.org/south-asians-for-abolitiondiasporic-strategies-and-conversations/ (accessed 7 June 2021).

Husain A (2020) Terror and abolition. Boston Review, 11 June. Available at: http://bostonreview.net/race/atiya-h usain-terror-and-abolition (accessed 1 June 2021).

Kaba M (2017) Towards the horizon of abolition: A conversation with Mariame Kaba by John Duda. The Next System Project, 9 November. Available at: https://thenext system.org/learn/stories/towards-horizon-abolition-con versation-mariame-kaba (accessed 3 June 2021).

Kauanui JK (2008) Hawaiian Blood: Colonialism and the Politics of Sovereignty and Indigeneity. Durham, NC: Duke University Press.

Kaur H (2021) "Fetishized, sexualized and marginalized, Asian women are uniquely vulnerable to violence." $C N N$, 17 March. Available at: www.cnn.com/2021/03/17/us/ asian-women-misogyny-spa-shootings-trnd/index.html (accessed 3 June 2021).

Kundnani A (2014) The Muslims Are Coming! Islamophobia, Extremism and the Domestic War on Terror. Brooklyn, NY: Verso Books.

Kuo R and Bhaman S (2021) Attacks on Asian women are fueled by criminalization, war and economic injustice. Truthout, 23 March. Available at: https://truthout.org/ articles/attacks-on-asian-women-are-fueled-by-criminaliza tion-war-and-economic-injustice/ (accessed 1 June 2021).

Law V (2021) "Prisons Make Us Safer": And 20 Other Myths about Mass Incarceration. Boston, MA: Beacon Press.

Lowe L (1998) "Work, immigration, gender: New subjects of cultural politics. Social Justice 25(3): 31-49.

Michel A (2015) "Countering violent extremism: Islamophobia, the Department of Justice and American Islamic Organizations. Islamophobia Studies Journal 3(1): 127-137.
Muhammad KG (2010) The Condemnation of Blackness: Race, Crime, and the Making of Modern Urban America. Cambridge, MA: Harvard University Press.

Muslim Justice League (2020) \#StopCVE Now. Muslim Justice League, May. Available at: www.muslimjustice league.org/wp-content/uploads/2020/05/FactSheet_Final_ version2_.pdf (accessed 1 June 2021).

Ngai M (2004) Impossible Subjects: Illegal Aliens and the Making of Modern America. Princeton, NJ: Princeton University Press.

Nguyen T (2021) The spectacle of Anti-Asian violence on Instagram. Vox, 14 April. Available at: https://www.vox. com/22374175/anti-asian-violence-images-instagram (accessed 1 June 2021).

Nopper T (2019) Digital character in "The Scored Society": FICO, social networks, and competing measurements of creditworthiness. In: Benjamin $\mathrm{R}$ (ed.) Captivating Technology. Durham, NC: Duke University Press, pp.170-187.

Nopper T (2021) Anti-Asian violence and Black-Asian solidarity today. In: Asian American writers' workshop, Youtube, 29 March. Available at: www.youtube.com/ watch? $=17$ MNPXHT0wM (accessed 1 June 2021).

@ NYPDCounterterrorism (2021) \#NYPDCT is monitoring the shooting of Asian Americans in Georgia... Twitter, 17 March. Available at: https://witter.com/NYPDCT/ status/1372011931922530309 (accessed 1 June 2021).

Ortiz J and Jackey H (2019) "The system is not broken, it is intentional: The prisoner reentry industry as deliberate structural violence". The Prison Journal 99(4): 484-503.

Purnell D (2019) Mass shootings, militarism and policing are chapters in the same manifesto. Truthout, 5 August. Available at: https://truthout.org/articles/mass-shootings-mil itarism-and-policing-are-chapters-in-the-same-manifesto/ (accessed 7 June 2021).

Reddy C (2011) Freedom with Violence: Race, Sexuality, and the US State. Duke University Press.

Richardson A (2020) Bearing Witness While Black: African Americans, Smartphones, and the New Protest \#Journalism. Oxford: Oxford University Press.

Roberts D (2020) Abolishing Policing Also Means Abolishing Family Regulation. Imprint News, 16 June. Available at: https://imprintnews.org/child-welfare-2/abolishing-polic ing-also-means-abolishing-family-regulation/44480 (accessed 3 June 2021).

Rodriguez D (2021) The Asian exception and the scramble for legibility. Society and Space, 8 April. Available at: https://societyandspace.webflow.io/articles/the-asianexception-and-the-scramble-for-legibility-toward-an-aboli tionist-approach-to-anti-asian-violence (accessed 1 June 2021).

Runes C (2017) Invisibility is an unnatural disaster. Urban Wire. Available at: www.urban.org/urban-wire/invisibili ty-unnatural-disaster-why-funding-2020-census-matterspacific-islanders (accessed 1 June 2021).

Stop LAPD Spying (2020) Surveillance bureaucracy expands the stalker state. Stop LAPD Spying, 24 June. Available at: https://stoplapdspying.org/surveillance-bureaucracyexpands-the-stalker-state/ (accessed 1 June 2021). 
Sutherland T (2019) The carceral archive: Documentary records, narrative construction, and predictive risk assessment. Journal of Cultural Analytics 1. https://doi.org/ 10.22148/16.039.

Sylvia Rivera Law Project (2009) SRLP On Hate Crime Laws. Sylvia Rivera Law Project, Available at: https:// srlp.org/action/hate-crimes/ (accessed 17 June 2021).

Takasaki K (2020) Stop AAPI hate reporting center: A model of collective leadership and community advocacy. Journal of Asian American Studies 23(3): 341-351.
Whitlock K, M and Bronski (2015) Considering Hate: Violence, Goodness, and Justice in American Culture and Politics. Boston, MA: Beacon Press.

White House (2021a) Memorandum condemning and combating racism, xenophobia, and intolerance against Asian Americans and Pacific Islanders in the United States. The White House, 26 January.

White House (2021b) FACT SHEET: President Biden announces additional actions to respond to Anti-Asian violence, xenophobia and bias. The White House, 30 March. 